$\mathbf{R}_{\text {ESEARCH }} \mathbf{P}_{\text {APER }} \longrightarrow$ FOOD SCIENCE

- Visit us : www.researchjournal.co.in Volume 9 | Issue 2 | October, 2018 | 434-440

DOI : $10.15740 / \mathrm{HAS} / \mathrm{FSRJ} / 9.2 / 434-440$

\title{
Studies on colour kinetics and textural characteristics of sugar and jaggery based papaya leather
}

\author{
Devendra Kumar and R.N. Shukla
}

Experimental studies were conducted to investigate the effect of various sweetener and citric acid levels on colour kinetics and textural characteristics of fresh as well as stored papaya leather. The levels of sweeteners were used as sugar, sugar $_{75}+$ jaggery $_{25}$, ,ugar $_{50}+$ jaggery $_{50}$, sugar $_{25}+$ jaggery $_{75}$ and jaggery with citric acid levels as 0.5 per cent, 0.75 per cent and 1.0 per cent. Developed papaya leather samples were evaluated for coulour kinetics and textural characteristics. Study revealed that brightness (L), redness (a) and yellowness (b) values deceased with increase in citric acid level in each treatment of sweeteners but these values increased during storage period with increase of citric acid level. Data showed that colour change value decreased with increase of citric acid level in samples using sugar as a sweetener. The chroma value decreased with increase of citric acid in all sweeteners. The hue angle increased with increase of citric acid level in papaya leather samples using sugar $_{50}+$ jaggery $_{50}, \operatorname{sugar}_{25}+$ jaggery $_{75}$ and jaggery as sweetener. The textural characteristics viz., hardness, cohesiveness, adhesiveness and springiness were obtained lowest as $32.7 \mathrm{~g}, 2.58,68.71 \mathrm{gs}$ and $2.74 \mathrm{~mm}$, respectively among the treatments of sweeteners whereas the gumminess and chewiness values were found highest in papaya leather sample using jaggery as a sweetener with 0.5 per cent citric acid level.

Key Words : Papaya leather, Sweetener, Citric acid, Colour kinetics, Textural

How to cite this article : Kumar, Devendra and Shukla, R.N. (2018). Studies on colour kinetics and textural characteristics of sugar and jaggery based papaya leather. Food Sci. Res. J., 9(2): 434-440, DOI : 10.15740/HAS/FSRJ/9.2/434-440.Copyright@ 2018: Hind Agri-Horticultural Society. 